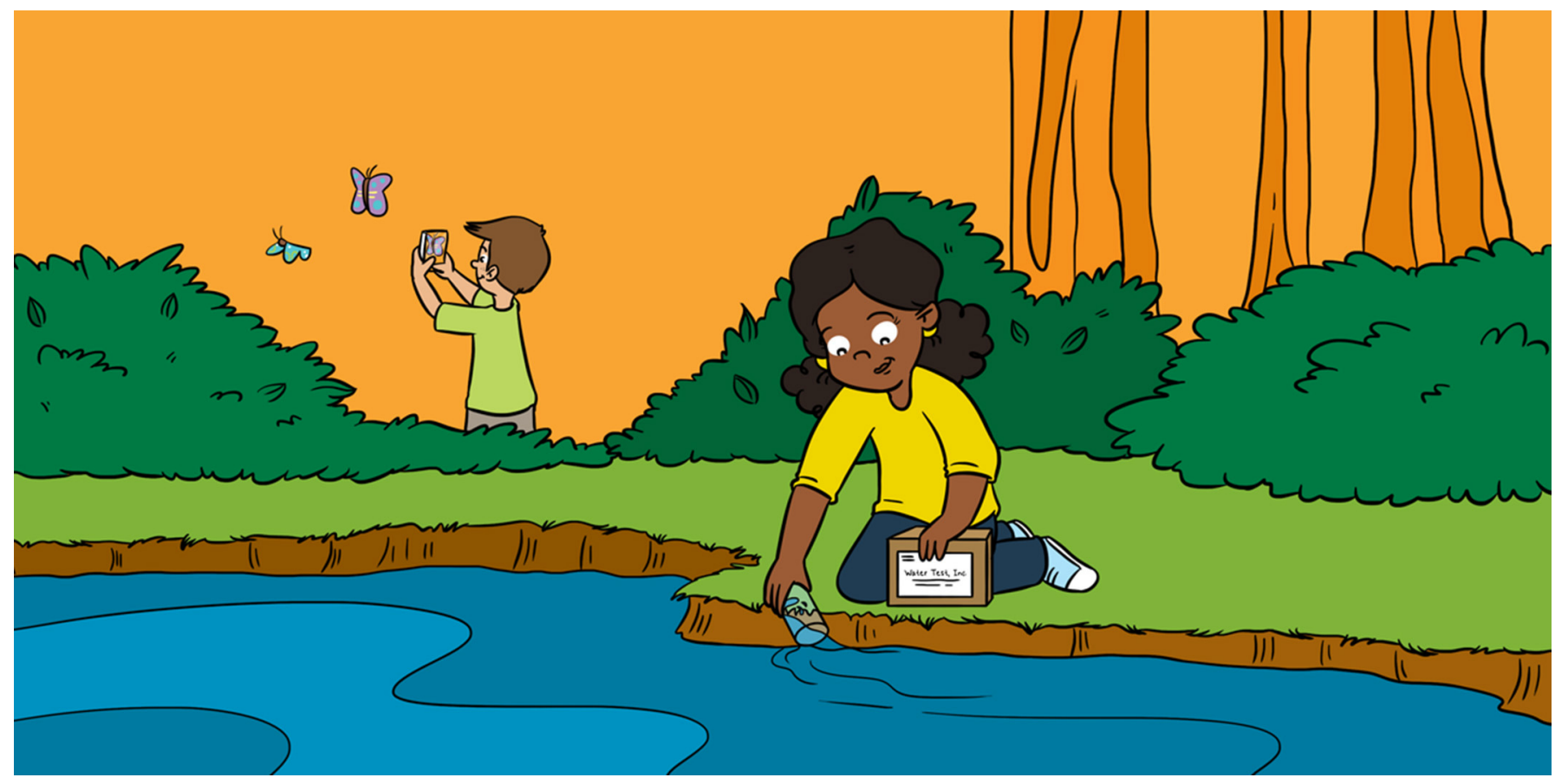

\title{
ON DARWIN'S STEPS: CITIZEN SCIENCE CAN HELP KEEP AN EYE ON ALIEN SPECIES
}

loannis Giovos ${ }^{1 *}$, Anastasia Charitou ${ }^{1}$, Eugenio Gervasini ${ }^{2}$, Celia López-Cañizares ${ }^{2}$, Konstantinos Tsiamis ${ }^{2}$ and Ana Cristina Cardoso ${ }^{2}$

${ }^{1}$ iSea, Environmental Organisation for the Preservation of the Aquatic Ecosystems, Thessaloniki, Greece

${ }^{2}$ Water and Marine Resources Unit, Directorate for Sustainable Resources, European Commission, Joint Research Centre (JRC), Ispra, Italy

YOUNG REVIEWERS:

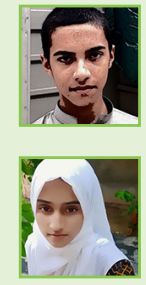

ABDUL

AGE: 14

SAMEEN

AGE: 14

ZAINAB

AGE: 12
Citizens around the world can act like scientists by providing important information about biodiversity that can help scientists' research. The same applies to species that expand from their areas of origin to other places, often creating problems for the native species. Nowadays, there are plenty of projects that involve citizen scientists in the monitoring of alien species and biodiversity. The European Alien Species Information Network (EASIN) of the European Commission gathers data from several projects and has developed its own app that enables people to report observations of invasive alien species. So, are you ready to become a citizen scientist?

\section{WHAT IS CITIZEN SCIENCE?}

Have you ever taken part in a global or local event focused on the environment, such as the celebration of World Water Day, World 


\section{CITIZEN SCIENCE}

The practice of public participation and collaboration in scientific research to increase scientific knowledge.

\section{NATIVE SPECIES}

A species that naturally occur in a particular ecosystem through history.

\section{BIODIVERSITY}

The variety of living things in the world or in a particular habitat or ecosystem.
Environment Day, World Fish Migration Day, or Earth Day? If you have participated in an event that involved observing nature, collecting information, and sharing this information with scientists, then you are a citizen scientist yourself!

Citizen science is the active involvement of the public in research. Through citizen science, people can engage in science in different ways depending on their locations and interests, and the data collected is shared with scientists (Figure 1). What type of activities does citizen science entail? One example is the testing of water quality in rivers by school students. This seems like a formal scientific activity, but students can participate and be citizens scientists, too. First, scientists train students on the methods and materials, and teach them about the data they need to collect and how it will be used. Then, students can collect and analyse samples from a river and send the results to the scientists. The data provided by the students are useful to help scientists monitor changes in the water quality of a river. Another example of a citizen science activity is the engagement of families and hikers in the monitoring of several native species of butterflies in national parks. Using a mobile app, they can record the species that they spot, supplying useful information to scientists about native butterflies. Citizen science can also be practiced under water! Divers can take photos of underwater life and upload them to an online platform created by scientists. The scientists can then identify the species, record their presence and expansion, and thus monitor underwater biodiversity.

The role of citizen scientists is important because scientists can analyze the information citizens provide [1], and as a result, propose measures for the protection of the environment. Did you know that Charles Darwin (1809-1882) and Jane Goodall (1934-) were citizen scientists when they started out? Can you imagine why? Because both were non-experts when they began!

\section{WHAT ARE THE PROS AND CONS OF CITIZEN SCIENCE?}

The impact of citizen science can be significant [1], but we should still consider the pros and cons of this method of data collection. Let us find out about some of them.

\section{Pros}

- Citizen scientists far outnumber scientists. As a result, they can collect a greater number of observations than scientists can.

- Citizen scientists can collect information from the different places of the world where they live. Without their help, experts would have to visit all those different places. This would require time and money.

- Citizen scientists may be more knowledgeable that scientists about local conditions. For example, locals know the most 
Figure 1

Citizen science activities. (A) Students monitoring invasive alien plants in Greece, submitting photos through a mobile app. (B) A Monarch butterfly is caught and tagged by a citizen scientist on behalf of Monarch Watch in Scarborough, Ontario, Canada. (C) Monitoring marine wildlife in the Icelandic fissure called Silfra by scuba diving. (D) Collection of data and clean-up of litter by a citizen scientist in the USA. (E) Citizen scientist collecting samples of river water in Asia, which will be sent to a lab for analysis. (F) Young citizen scientist with binoculars, birdwatching in the summer forest in Canada.

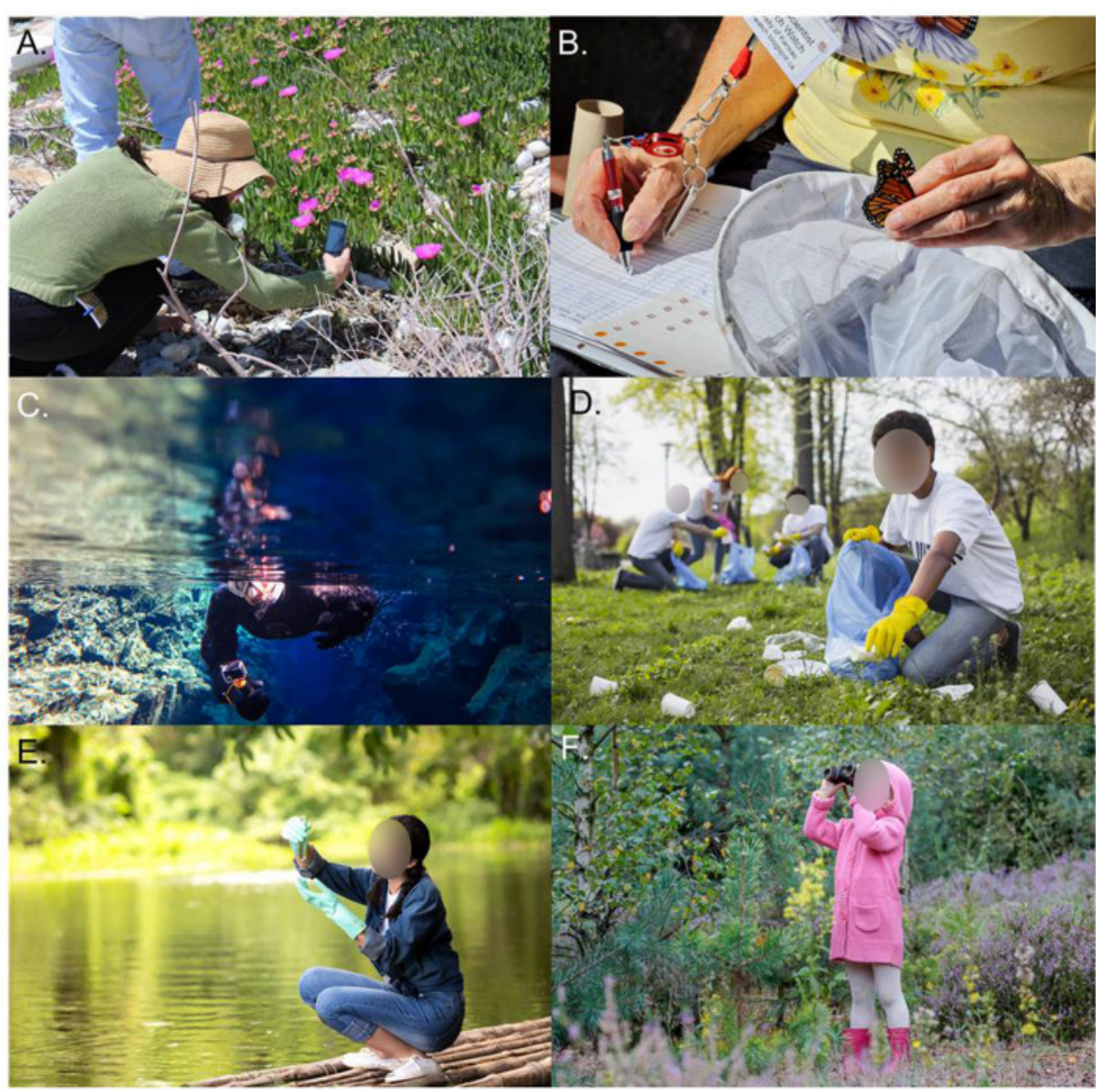

Figure 1

common species in their areas and where to find them, like fishers and farmers. These people provide information that scientist call local ecological knowledge.

- The more citizens scientists take part, the more information they collect. So, there are more chances of detecting rare events and understanding changing phenomena. If a new species occurs in an area, what are the chances that a single scientist will run into it?

- It is a rewarding activity! Citizen scientists contribute to our knowledge about important issues. They also interact with scientists, and in doing so enrich their own knowledge.

- Citizen scientists have a strong motivation to explore the environment, so, they spend more time outdoors. This strengthens their relationship with nature. They are also curious, which encourages them to gain new knowledge.

- Citizen scientists have made great discoveries! Many of them have discovered stars for the first time and, in 2019, a citizen scientist discovered a new planet!

- Tools provided to citizen scientists can be simple, fun, and easy to use, for instance, mobile phone apps and social media! 


\section{Cons}

- Some projects are demanding and require precise procedures for obtaining scientifically sound results. Strict procedures can discourage some citizen scientists. For example, some projects aim to recognize plants of an area. Scientists need photos of certain features of plants to be able to identify them. If they are not available and accessible citizen scientist cannot provide accurate data.

- Citizen scientists' data needs to be double checked by scientists, which requires time and effort. For example, scientists must crosscheck to eliminate double records and to see whether information sent by citizen scientists represents new information.

- Checking the information gathered by citizen scientists may require collaboration among scientists with different expertise. Some projects aim to collect information on all the species in an area. So, experts on each group of species may need to collaborate. For example, specialists on birds and plants. These collaborations can sometimes be difficult to organize.

- Demanding projects require extra time and resources for the training of citizen scientists. Citizens who take part in these projects need a strong motivation and are not easy to find!

Despite the several challenges that citizen science projects may pose, the benefits far exceed the difficulties. For example, citizen science can be crucial for the protection of species that are threatened for extinction [2].

\section{ALIEN SPECIES}

Species that are introduced accidentally or deliberately by humans into a new environment, far away from the area where they have evolved and adapted for thousands of years.

\section{NATIVE RANGE}

A species range is an area where a particular species can be found during its lifetime.

\section{WHAT ARE ALIEN SPECIES AND WHAT PROBLEMS ARE THEY CAUSING?}

We can define alien species as organisms that are found in areas different from where they originated. Through human activities, alien species can travel to new places outside their native ranges. For example, before 1850, not a single camel lived in Australia. Camels were imported to Australia from the Arabian Peninsula because they could stand the Australian weather conditions and were therefore an ideal means of transport. But camels are alien species to Australia and have developed wild populations that are increasing in size. Also, insects may enter remote countries by traveling on plants that are traded for agriculture or ornamental purposes. In the case of plants, travelers' footwear can transfer seeds to other continents. Additionally, exotic pets obtained from other countries may escape from their cages. For instance, the California kingsnake was transported to Gran Canaria Island as a pet. Now it is found in the wild, affecting the island's native animals.

Once in these new places, alien species may survive, reproduce, and spread further [3]. The new environment might be different than what 
INVASIVE SPECIES

Alien species that have grown a large population in the new environment where they were introduced. Invasive species may cause significant changes in the environment.

\section{ECOSYSTEM}

\section{SERVICES}

Are the many and varied benefits to humans provided by the natural environment.

they are used to, so, survival is a hard task. Some species can adapt to new temperatures, feed on new resources, and survive in new soils or shelters. Some alien species can play positive roles in their new homes. They may provide new habitats or food resources for species already living there. In many other cases, alien species have negative impacts. They need food, light, water, nesting places, and spaces to root and grow. Alien species can compete with and displace native species. In some cases, alien species even transmit diseases to native species. When an alien species has a negative impact in the new ecosystems, it is called an invasive species.

\section{WHY IS IT IMPORTANT TO MONITOR ALIEN SPECIES?}

Ecosystems provide humans with food, water, air, soil, and recreation opportunities. Altogether, the benefits that nature provides to humans are called ecosystem services. To provide these services to humans, ecosystems must be healthy. The biodiversity of an ecosystem is important, and invasive alien species are one of the most significant factors disturbing the balance of ecosystems by threatening local biodiversity. Scientists and environmental managers have been studying alien species for many years to understand how alien species are introduced, how they become invasive, and how to protect native species and the health of ecosystems from invasive species. So, the priority of environmental managers is to prevent the introduction of alien species. Simultaneously, scientists continue studying which alien species have been introduced, how many there are, and where they are located [1]. Then, scientists and environmental managers can look for ways to manage alien species.

\section{HOW YOU CAN HELP?}

Citizens can help to protect native ecosystems from invasive alien species through citizen science! Scientists cannot be everywhere, monitoring every single place on land and sea [4]. But people visit different places every day. They spend time near forests, rivers, lakes, seacoasts, urban parks, and many other ecosystems. Citizens can collect information on alien species in various areas, helping scientists to monitor these ecosystems. In Europe, there are many ongoing citizen science projects. Several focus on alien species, monitoring their presence, populations, and expansion. You can find the list of these projects by following the link in Figure 2. By joining one of these projects, people can contribute the pool of information that will help scientists reduce the impact of invasive alien species. 


\section{Figure 2}

(A) European countries with citizen science organizations and projects registered in the European Alien Species Information Network (EASIN) of the European Commission. (B) Number of citizen science projects related to alien species by country, registered in EASIN's database. More information about the projects and links to their websites can be found at https://easin. jrc.ec.europa.eu/easin/ CitizenScience/Projects

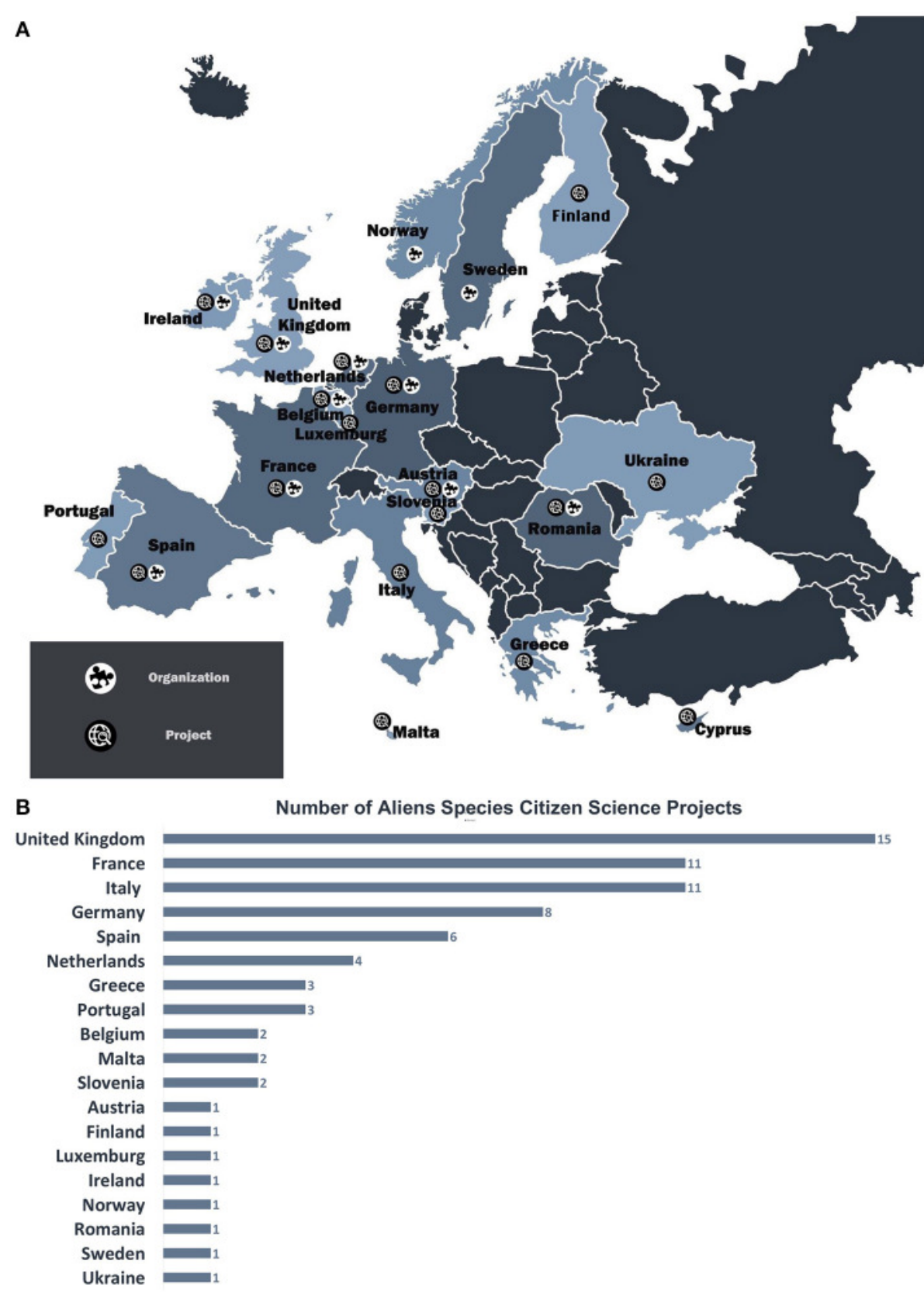

Figure 2

\section{THE "INVASIVE ALIEN SPECIES IN EUROPE" APP}

Who works on alien species in Europe? Many organizations do, including a directorate of the European Commission that manages the European Alien Species Information Network (EASIN) (Figure 2). This organization collects and harmonizes information on alien species from different sources and makes it available to the public. The EASINlit uses scientific findings and official reports from countries belonging to the European Union. In addition, it collects records from citizen scientists through a smartphone app (Figure 3). 
Figure 3

The smartphone app Invasive Alien Species Europe can be used by everyone that wants to help in monitoring invasive alien species of Union Concern within Europe.

INVASIVE ALIEN

SPECIES OF UNION

\section{CONCERN}

Invasive alien species with a negative impact on biodiversity in Europe, requiring the collaboration between countries from the European Union member for their detection, monitoring, and control.

1 European Alien Species Information Network (EASIN) of the European Commission (2019). Available online at: https://digitalearthlab. jrc.ec.europa.eu/ app/invasive-alien -species-europe

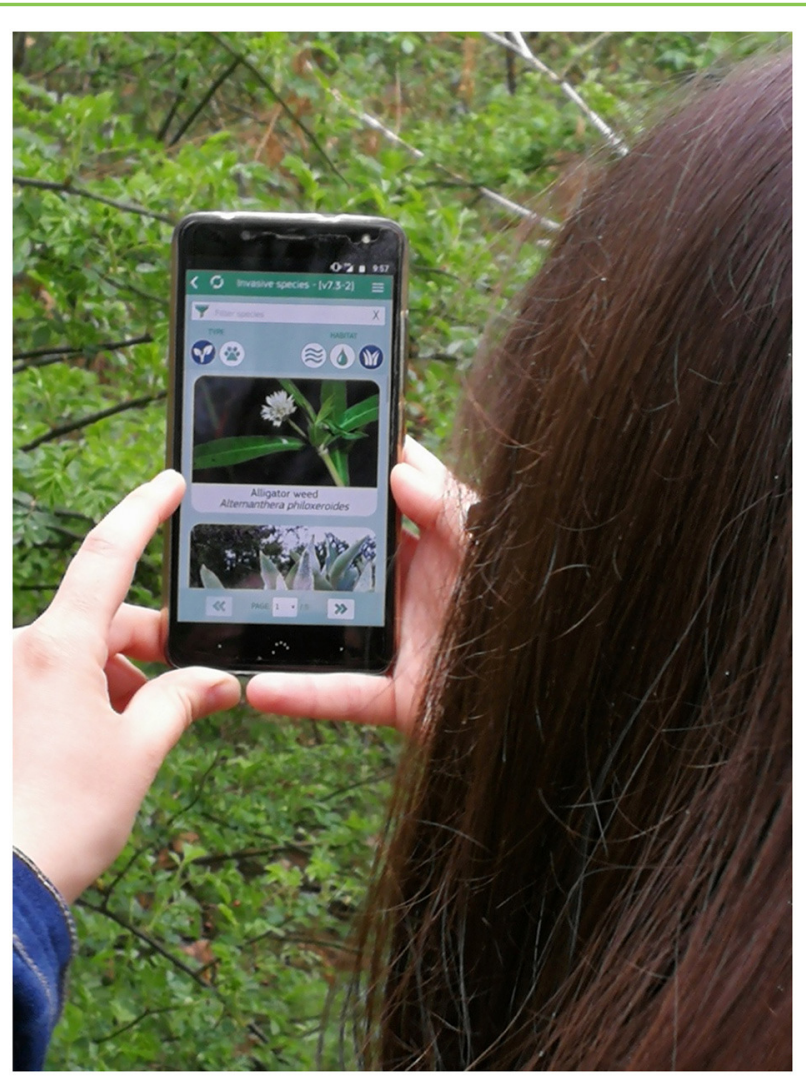

Figure 3

There are some invasive alien species with high negative impacts in Europe, and they are called species of Union concern ${ }^{1}$. The EASIN app includes pictures and information on all 66 invasive alien species of Union concern: 30 animal species and 36 plant species [5]. App users can take pictures of the species they observe and submit them using the "Report a sighting" feature of the app. Once information is submitted, EASIN and a network of scientists validate the data, discarding incorrect submissions, and correcting information if necessary. For example, if a tree is reported as growing in the sea because the GPS was not working correctly at the time of submission, the location can be corrected, and feedback is sent to the citizen scientist.

Can you imagine the results? Citizens are becoming active and sending their observations of invasive alien species of Union concern to the EASIN, which makes the data publicly accessible, helping with the monitoring of these species. Is this important? The answer is YES! It is particularly important for early detection of alien species, helping scientists and environmental managers to quickly take action. Scientists also use information provided by citizen science to propose laws to protect local ecosystems from alien species. For example, scientists discovered that some fish considered to be invasive alien species of Union concern were being released into nature from 
people's aquariums. So, they proposed a measure to prohibit the trade of these fish for aquariums, to protect our lakes, rivers, and seas.

\section{CONCLUSION}

Citizen science is an important participatory activity that is becoming increasingly popular in our society. Every day, more projects on nature protection are arising worldwide, thanks to the interest and willingness of the public to participate. Through the monitoring of invasive alien species, people can help scientists and contribute to the protection of local ecosystems. The contribution of citizen scientists can make a huge difference in the early detection of alien species and help scientists to understand how these species expand. Observations by citizen scientists help scientists and environmental managers to look for solutions to protect local ecosystems. Participation in citizen science activities also improves people's relationship with nature in the long term, making them more prone to protect our planet. You can too become a citizen scientist and continue helping to protect our planet.

\section{ACKNOWLEDGMENTS}

The authors would like to thank the COST Action CA17122, that funded IG, in the context of the Short Term Scientific Mission CA17122 - Increasing understanding of alien species through citizen science, to produce this work. Additionally, the authors would like to thank all reviewers for their constructive comments.

\section{REFERENCES}

1. Chandler, M., See, L., Copas, K., Bonde, A. M., Lopez, B. C., Danielsen, F., et al. 2017. Contribution of citizen science towards international biodiversity monitoring. Biol. Conserv. 213:280-94. doi: 10.1016/j.biocon.2016.09.004

2. Seebens, H., Blackburn, T. M., Dyer, E. E., Genovesi, P., Hulme, P. E., Jeschke, J. M., et al. 2017. No saturation in the accumulation of alien species worldwide. Nat. Commun. 8:14435. doi: 10.1038/ncomms14435

3. Lloyd, T. J., Fuller, R. A., Oliver, J. L., Tulloch, A., Barnes, M., and Steven, R. 2020. Estimating the spatial coverage of citizen science for monitoring threatened species. Glob. Ecol. Conserv. 23:e01048. doi: 10.1016/j.gecco.2020.e01048

4. Jonson, B. A., Mader, A. D., Dasgupta, R., and Kumar, P. 2020. Citizen science and invasive alien species: an analysis of citizen science initiatives using information and communications technology (ICT) to collect invasive alien species observations. Glob. Ecol. Conserv. 21:e00812. doi: 10.1016/j.gecco.2019.e00812

5. Cardoso, A., Tsiamis, K., Gervasini, E., Schade, S., Taucer, F., Adriaens, T., et al. 2017. Citizen science and open data: a model for invasive alien species in Europe. Res. Ideas Outcomes 3:e14811. doi: 10.3897/rio.3.e14811 
SUBMITTED: 14 December 2019; ACCEPTED: 09 February 2021;

PUBLISHED ONLINE: 19 March 2021.

EDITED BY: Vishal Shah, West Chester University, United States

CITATION: Giovos I, Charitou A, Gervasini E, López-Cañizares C, Tsiamis K and Cardoso AC (2021) On Darwin's Steps: Citizen Science Can Help Keep an Eye on Alien Species. Front. Young Minds 9:520201. doi: 10.3389/frym.2021.520201

CONFLICT OF INTEREST: The authors declare that the research was conducted in the absence of any commercial or financial relationships that could be construed as a potential conflict of interest.

COPYRIGHT () 2021 Giovos, Charitou, Gervasini, López-Cañizares, Tsiamis and Cardoso. This is an open-access article distributed under the terms of the Creative Commons Attribution License (CC BY). The use, distribution or reproduction in other forums is permitted, provided the original author(s) and the copyright owner(s) are credited and that the original publication in this journal is cited, in accordance with accepted academic practice. No use, distribution or reproduction is permitted which does not comply with these terms.

\section{YOUNG REVIEWERS}
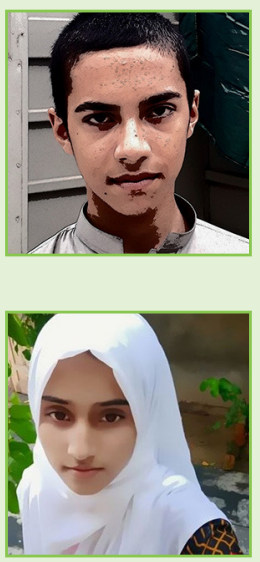

\section{ABDUL, AGE: 14}

Abdul is very much interested in nature and diversity. It is of great fun to him to discover and about unknown creatures. He is enthusiastic to learn about new species under the water and at the top of mountains, inside the jungle and far away in the deserts.

\section{SAMEEN, AGE: 14}

Hello, I am Sameen from Mandi Bahauddin (M.B.Din). My school is very competitive especially in science subjects but I like biology. I like to know about natural processes especially in aquatic species. I love to read newspaper, history books, and learn new languages. Besides, I wish to participate in environmental clubs and field trips. I want to study the ecosystems and biology when I grow up.

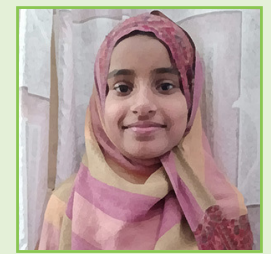

\section{ZAINAB, AGE: 12}

$\mathrm{Hi}$, my name is Zainab and I belong to a village situated in Phalia. I am interested in species relations and the environmental changes. That is why I am interested in Biology and want to learn more about biological species. I like to read about the latest news in biology. Apart from that, I want to learn about the history of species and the environment. I like to go into the country side and see the plants and animal species. I am also ready to take part in the online learning activities related to biology. 

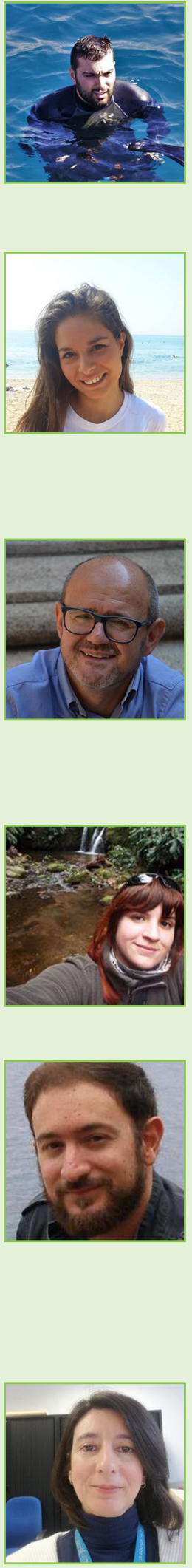

\section{AUTHORS}

\section{IOANNIS GIOVOS}

loannis Giovos is the Fisheries Director of iSea, an Environmental Organisation based in Thessaloniki Greece. He is working for over 10 years on the conservation of the Mediterranean with an interest in the conservation of marine biodiversity. His research focuses on policy, fisheries research, citizen science, local ecological knowledge, iEcology, and public perception. *ioannis.giovos@isea.com.gr

\section{ANASTASIA CHARITOU}

Anastasia Charitou is the Director of environmental education projects of iSea, a Greek Environmental Organisation. She has 4 years of experience in formal education and for the last 5 years has been responsible for the implementation of iSea's environmental education projects focusing on students and other stakeholder groups. Her research focuses on public perception and knowledge of marine litter

\section{EUGENIO GERVASINI}

Eugenio Gervasini is graduated in Agricultural Sciences, and specialized in Integrated Pest Management and biological control. He coordinated applied research concerning harmful organisms and their biological control in glasshouses, nurseries, forests, and in the urban and natural environment, as well as surveys for quarantine pests. Eugenio is a member of the EASIN Team and is particularly involved in Citizen Science activities and communication.

\section{CELIA LÓPEZ-CAÑIZARES}

Celia López Cañizares is a biologist working on citizen science, social media, and communication at the European Alien Species Information Network-EASIN. Her areas of interest are terrestrial ecology, science promotion, and environmental education.

\section{KONSTANTINOS TSIAMIS}

Konstantinos Tsiamis is a biologist, specialized in biodiversity and alien species. $\mathrm{He}$ is involved with supporting the implementation of EU environmental policies and the coordination of wide groups of experts. He provides scientific support on the EU information system on alien species (EASIN); pollution impacts and coastal management are also included among his fields of interest. He has participated in $>40$ research projects and is (co)author of $>70$ publications in peer-review international journals.

\section{ANA CRISTINA CARDOSO}

Ana Cristina Cardoso is an aquatic ecologist and is responsible for the coordination of the European Alien Species Information Network (EASIN). She has 25 years' experience in science for policy support in the fields of freshwater and marine ecology. Her current research interests include the assessment of alien invasive species pressure and impacts on natural ecosystems. 